The Role of Cultural Discontinuity in the Academic Outcomes of Latina/o High School Students

Amanda Taggart

California State University, Bakersfield 


\begin{abstract}
This study examined the impact of cultural discontinuity on the academic outcomes of Latina/o high school students. Hierarchical multiple regression was utilized to (a) investigate the significant differences between the characteristics and academic outcomes of high school students who do and do not experience cultural discontinuity between their home- and schoolbased learning and social experiences based on Eurocentric cultural values, and (b) examine the contribution of demographic variables, socio-cultural variables, academic experiences, and cultural discontinuity to students' cumulative grade point average (GPA) and standardized test scores. Data were collected from two high schools in South Central Texas. Findings revealed that cultural discontinuity had an inverse relationship with GPA; therefore, the more cultural discontinuity based on Eurocentric cultural values that a student experienced, the lower was the student's GPA.
\end{abstract}

Keywords: cultural discontinuity, Latina/o students, high school 


\section{The Role of Cultural Discontinuity in the Academic Outcomes of Latina/o High School}

\section{Students}

Latinas/os currently make up the largest racial/ethnic minority group in the United States (National Center for Education Statistics, 2010a), and as the national population of Latinas/os has increased, so has their enrollment in U.S. public schools, accounting for one fourth of all public school students (M. H. Lopez \& Fry, 2013). Latina/o students make up more than half of students in California, New Mexico, and Texas, and are the largest minority group in public schools in 23 other states (National Center for Education Statistics, 2013). However, as has been well documented, there exists a wide gap between the educational achievement of Latina/o students and their White peers. For example, Latina/o students as a whole currently score lower on standardized tests than White students (National Center for Education Statistics, 2010b) and have higher dropout rates than all other racial/ethnic groups except for American Indians/Alaska Natives (Stark \& Noel, 2015). Even among those students who graduate from high school and enroll in college, Latinas/os have lower bachelor's degree completion rates than their African American, Asian, and White peers (M. H. Lopez \& Fry, 2013; National Center for Education Statistics, 2010a)

Although Latinas/os comprise a large and ever-growing portion of public school students, it is worthwhile to note that White teachers make up $82 \%$ of the teaching force in all U.S. public schools (Goldring, Gray, \& Bitterman, 2013). Because White teachers are assumed to present and validate Eurocentric values and behaviors in their classrooms, as opposed to differing values that their racial/ethnic minority students may bring with them from home to school (Boykin, Tyler, \& Miller, 2005; Delpit, 2006; Sue, 2004), cultural discontinuity is one concept that has been linked to the academic difficulties of racial/ethnic minority students (Baker, 2005; Boykin, 
Tyler, \& Miller, 2005; Cartledge \& Loe, 2001; Foster, Lewis, \& Onafowora, 2003; LadsonBillings, 1995b). Cultural discontinuity is conceptually defined as "a school-based behavioral process where the cultural value-based learning preferences and practices of many ethnic minority students - those typically originating from home or parental socialization activitiesare discontinued at school" (Tyler et al., 2008, p. 281). Researchers have utilized the idea of cultural discontinuity to further explain the dynamics behind racial/ethnic minority student success or failure, hypothesizing that students who feel more culturally aligned with the school systems of which they are part will feel more motivated (Hudley \& Daoud, 2008) and be more academically successful (Warzon \& Ginsburg-Block, 2008), whereas cultural discontinuity may contribute to poor academic and psychological outcomes in culturally diverse students in schools (e.g., Cholewa \& West-Olatunji, 2008; Deyhle, 1995; Lui, 2015). Although there may be discontinuities between the home and school lives of any student, home-school discontinuities are assumed to be more pronounced for racial/ethnic minority students (Cartledge \& Loe, 2001; Ladson-Billings, 1995a).

Culture has been defined as "the unique values, symbols, lifestyles, institutions, and other human-made components that distinguish one group from another" (Banks, 2007, p. 119) and has been shown to influence cognitive and behavioral development (e.g., American Psychological Association, 2003; Constantine \& Sue, 2006; Lovelace \& Wheeler, 2006). Although it is widely recognized that varying degrees of heterogeneity may exist within cultural groups (e.g., Warikoo \& Carter, 2009), and the author in no way suggests that all individuals exhibit or endorse cultural values frequently associated with their ethnic groups (e.g., Tyler et al., 2008), it is also commonly acknowledged that regularities in values and behaviors may be 
shaped by individual and group participation in cultural experiences and practices (American Psychological Association, 2003; Gutiérrez \& Rogoff, 2003).

One cultural context that greatly influences cognitive development is the U.S. public school. Far from being culture-free, instruction in mainstream schools represents specific cultural values and beliefs (e.g., Cholewa \& West-Olatunji, 2008; Ornstein, Levine, \& Gutek, 2011), particularly individualism (e.g., American Psychological Association, 2003; Durden, 2007; Schwartz et al., 2013) and competition (Boykin, Tyler, \& Miller, 2005; Durden, 2007; Garrett, Bellon-Harn, Torres-Rivera, Garrett, \& Roberts, 2003). However, because families are considered to contribute most directly to the early socialization and education of children (Ornstein et al., 2011), these mainstream values may not reflect the cultural values of many racial/ethnic minority students (Cartledge \& Loe, 2001; Deyhle, 1995; Durden, 2007). For example, one of the specific cultural themes that has been best researched in the home socialization activities of Latina/o students and their parents is the value of collectivism (e.g., Greenfield, Keller, Fuligni, \& Maynard, 2003; S. G. Lopez, Garza, \& Gonzalez-Blanks, 2012; Mejía-Arauz, Rogoff, Dexter, \& Najafi, 2007; Mosier \& Rogoff, 2003).

In turn, the purpose of this study was to examine the relationship between cultural discontinuity and the academic achievement of Latina/o secondary students, and was guided by the following research questions:

Research Question 1: Are there significant differences between the characteristics and academic achievement of Latina/o high school students who do and do not experience cultural discontinuity between their home- and school-based learning and social experiences? 
Research Question 2: What is the contribution of demographic variables, socio-cultural variables, academic experiences, and cultural discontinuity to Latina/o students' grade point average (GPA) and mathematics standardized test scores?

A study of cultural discontinuity and its influence on Latina/o students' academic achievement is important for several reasons. First, whereas previous research has examined the cultural variables that may impact racial/ethnic minority student achievement, this research has often been conducted with students of varying races, ethnicities, and ages, with the findings then being generalized to other underserved groups or students of different ages. In response, the present study is specific to high school students, whereas prior research has largely examined cultural discontinuity in relation to elementary school-age students (e.g., Boykin, Tyler, WatkinsLewis, \& Kizzie, 2006; Tyler, Boykin, \& Walton, 2006). Next, although an understanding of the relationship between factors that improve or impair learning can help to advance both research and practice for all students, the study of cultural discontinuity in regard to Latina/o high school students has heretofore been largely overlooked in the literature as the majority of previous studies on cultural discontinuity have investigated the idea as it relates to other racial/ ethnic and cultural heritage groups (e.g., Arunkumar, Midgley, \& Urdan, 1999; Boykin \& Cunningham, 2001; Kearney, Fletcher, \& Dobrenov-Major, 2011). Therefore, the specific focus on Latina/o students in this study advances research explicit to this group.

In addition, by examining cultural discontinuity, educators can gain insight into how to develop teaching strategies for and make meaningful connections with Latina/o students, which may help to reduce many of the educational obstacles faced by them (Beachum \& McCray, 2008). Knowledge of the cultural values and cultural value-based behaviors to which Latina/o students have been socialized, and the impact these values have on student achievement, can 
serve as invaluable input into the pedagogical and leadership decisions of teachers and school administrators seeking to eliminate Latina/o high school students' marginalization in schools (Theoharis, 2007, 2008), and to promote equitable achievement outcomes for all students through culturally responsive educational environments and curriculum.

The study also contributes to the existing literature by investigating the existence of cultural discontinuity between the home and school lives of Latina/o students, as well as examining the impact cultural discontinuity may have on students' academic achievement. To date, there has been little empirical research demonstrating that cultural discontinuity in schools is more prevalent for racial/ethnic minority students than for other students. According to Tyler et al. (2008), "Cultural discontinuity should be premised not on perceptions of its existence but rather on ethnic minority students' actual reported frequency of cultural value-based behaviors both at home and at school" (p. 292). In turn, this study addresses limitations in prior research by concurrently assessing students' perceptions of how often cultural value-based behaviors occur in their homes and in their schools (Losey, 1995; Tyler et al., 2008), whereas previous studies have focused mainly on either the home or school settings (e.g., Boykin, Tyler, \& Miller, 2005; Tyler, Boykin, Boelter, \& Dillihunt, 2005).

\section{Theoretical Framework and Related Literature}

The following section offers a conceptual framework developed from relevant literature, which hypothesizes that racially and ethnically diverse high school students' academic outcomes are associated with (a) demographic variables, (b) socio-cultural variables, (c) academic experiences, and (d) cultural discontinuity. As discussed in the following paragraphs, the variables in the model for this study were drawn from a deep search of prior research specific to Latina/o students' academic success (e.g., Plunkett \& Bámaca-Gómez, 2003; Sciarra \& Whitson, 
2007), cultural discontinuity (e.g., Boykin, Albury, et al., 2005; Tyler et al., 2006), and certain cultural values theorized to be prevalent in Eurocentric and Latina/o groups (e.g., Greenfield et al., 2003; Mejía-Arauz et al., 2007; Rogoff, 2003). The model theorizes that students' academic achievement, as measured by GPA and standardized test scores, is shaped by numerous demographic and socio-cultural variables, academic experiences, and cultural discontinuity. Each of these variables is reviewed below.

Existing work has shown that several demographic variables influence Latina/o academic achievement, including gender (e.g., Plunkett \& Bámaca-Gómez, 2003; Santiago, Gudiño, Baweja, \& Nadeem, 2014; Sciarra \& Whitson, 2007), language spoken at home (e.g., Zarate \& Pineda, 2014; Zwick \& Sklar, 2005), generational status (e.g., Bankston \& Zhou, 2002; Padilla \& Gonzalez, 2001; J. L. Rodriguez, 2002), and socio-economic level (e.g., Barrett, Barile, Malm, \& Weaver, 2012; Clark, Ponjuan, Orrock, Wilson, \& Flores, 2013; O’Connor, 2009).

Moreover, with the exception of a few studies (e.g., Goldenberg, Gallimore, Reese, \& Garnier, 2001), research findings to date have shown that academic success among Latina/o students is positively related to socio-cultural variables such as parental education levels (e.g., Hannon, 2015; Plunkett \& Bámaca-Gómez, 2003; Plunkett, Behnke, Sands, \& Choi, 2009). Within the body of literature on academic experiences and Latina/o achievement, grades have been shown to significantly affect Latina/o students' predispositions to attend college (Hamrick \& Stage, 2004), and overall research findings to date indicate that higher levels of rigor in course-taking patterns result in higher academic achievement (e.g., Gonzalez, Stoner, \& Jovel, 2003; Mosqueda \& Maldonado, 2013). In addition to rigorous academic preparation in general, mathematics preparation in particular is a factor that has been shown to contribute to the educational success of students (e.g., Huerta, Watt, \& Reyes, 2013; Sciarra \& Whitson, 2007). 
For example, declines or improvements in mathematics performance in high school have been shown to be better predictors of college-prep GPA, college eligibility, and type of college attended than are grades in English (C. R. Cooper, Cooper, Azmitia, Chavira, \& Gullatt, 2002).

In addition, researchers have found that cultural discontinuity may have negative psychological and academic outcomes for racial/ethnic minority students (e.g., Arunkumar et al., 1999; Cholewa \& West-Olatunji, 2008; Deyhle, 1995; Vasquez-Salgado, Greenfield, \& BurgosCienfuegos, 2015; Warzon \& Ginsburg-Block, 2008), and prior work also suggests that mainstream teachers' attitudes and behavior toward students with whom they perceive themselves to have differences is often detrimental to student success (e.g., Hauser-Cram, Sirin, \& Stipek, 2003; Tan, 2001, 2002; Thompson, Warren, \& Carter, 2004).

In regard to cultural discontinuity, there is a substantial body of research in educational anthropology, sociology, and psychology on Latina/o cultural values and academic achievement. The early focus of many educational researchers beginning around the 1970s was on issues of cultural incongruence and academic performance (see Cazden, John, \& Hymes, 1972, for an early example of work in this area). In addition, Ogbu's (1982) work explicitly critiqued cultural mismatch theories and their influence on racial/ethnic minority student performance. Scholars since the 1990s have continued to discuss cultural discontinuity, variously terming it cultural mismatch (e.g., Ladson-Billings, 1995b), cultural incongruence (e.g., Foster et al., 2003), cultural misalignment (e.g., Tyler et al., 2006), cultural dissonance (e.g., Ladson-Billings, 1995b; Portes, 2001; Tillman, 2002), cultural conflict (e.g., Foster et al., 2003), and cultural collision (Beachum \& McCray, 2008). In addition, much of this research has been conducted on African American cultural values and their impact on the educational consequences of African American students (e.g., Boykin, Albury, et al., 2005; Boykin \& Cunningham, 2001; Boykin, Tyler, \& Miller, 2005; 
Komarraju \& Cokley, 2008; Marryshow, Hurley, Allen, Tyler, \& Boykin, 2005; Tyler et al., 2006). The aim of the present study is to extend the research on African American students to Latina/o students and the effect of cultural discontinuity on their academic achievement. The subsequent section synthesizes the literature to date on certain cultural values said to pervade mainstream, or Eurocentric, U.S. society and educational institutions, as well as those values often studied in Latina/o culture, the mismatch of which may result in students experiencing cultural discontinuity between home and school.

\section{Mainstream Cultural Values}

The cultural values considered to be most prevalent in mainstream U.S. society are individualism and competition. Individualism encompasses the ideas of autonomy, independence, individual recognition, solitude, and the exclusion of others (Tyler et al., 2008), and is a cultural value toward which many European Americans have been socialized since birth (Morelli, Rogoff, Oppenheim, \& Goldsmith, 1992). It is a trait that many consider central to the U.S. psyche and is reflected in the Eurocentric values of U.S. schools, where the focus is most often on independent academic achievement (Glass \& Rud, 2012; Greenfield et al., 2003; Greenfield \& Quiroz, 2013; Rothstein-Fisch, Trumbull, \& Garcia, 2009).

Competition refers to an individual performing better than others (Tyler et al., 2008) and is also viewed as a central element of life in the United States (e.g., Rogoff, 2003). Prior research has lent support to the salience of individualism and competition among European Americans in U.S. schools (e.g., Slavin, 1982) and has been cited as the standard with which all students are compared and graded (La Roche \& Shriberg, 2004). For example, in their study on prevalent cultural themes observed in six elementary schools in an urban city in the Midwest, Boykin, Tyler, and Miller (2005) found that individualism was the most frequently occurring cultural 
theme in 52 classroom observations. In addition, Boykin, Albury, et el. (2005) found, in their study of two racially integrated public schools in an urban southeastern city, that European American students were significantly more accepting of individualistic and competitive high achievers than were African American students, who endorsed communal behaviors significantly more than the European American students.

\section{Latina/o Cultural Values}

In contrast to Eurocentric cultural values, one of the most researched culturally based values considered to be held by many Latinas/os is collectivism (e.g., González-Prendes, Hindo, \& Pardo, 2011; Greenfield, Flores, Davis, \& Salimkhan, 2008; Guilamo-Ramos et al., 2007; Halgunseth, Ispa, \& Rudy, 2006; S. G. Lopez et al., 2012; Marsiglia, Parsai, \& Kulis, 2009; Segal, Gerdes, Mullins, Wagaman, \& Androff, 2011; Shorey, Cowan, \& Sullivan, 2002). Collectivism is often viewed as the opposite of individualism, and is similar to familism in relation to Latina/o groups (Esparza \& Sánchez, 2008). Collectivism is defined as the fundamental interdependence of people, in which "social responsibility is centered on the good of the whole group or family, and a person's responsibilities are geared toward advancing or maintaining the group" (Tyler et al., 2008, p. 287).

Studies examining collectivism (e.g., Mejía-Arauz et al., 2007; Rogoff, Mistry, Göncü, \& Mosier, 1993) include work by Vélez (1983, as cited in Vélez-Ibáñez, 1996), who examined variations in the mothering styles of Mexican American and Anglo women and found greater social density among the Mexican American families in the sample, indicating stronger collectivistic orientation at a young age for the Mexican American children in the study. Complementing these findings is research conducted by Mosier and Rogoff (2003), who studied the habits of Guatemalan and U.S. mothers and children and found that very young Guatemalan 
children were already expected to contribute to collective family life whereas U.S. children were not yet held responsible to do so.

In addition, familism has been shown to influence educational, psychological, and behavioral outcomes of Latina/o students (Vasquez-Salgado et al., 2015). It has been shown to be positively associated with academic effort and negatively related to truancy (Esparza \& Sánchez, 2008). It has also been found to help student grades if a student's parents attained at least a high school education (Valenzuela \& Dornbusch, 1994) and has been found to be a predictor of college application rates and patterns (Desmond \& López-Turley, 2009). Furthermore, familism has been shown to be positively related to psychological well-being (N. Rodriguez, Mira, Paez, \& Myers, 2007) and negatively related to depressive symptoms (Cupito, Stein, \& Gonzalez, 2015; McHale, Updegraff, Kim, \& Cansler, 2009). It has also been found to act as a protective factor against aggression, conduct problems, rule-breaking, and other risktaking behaviors (Rudolph, Cornelius-White, \& Quintana, 2005; Umaña-Taylor, Updegraff, \& Gonzales-Backen, 2011).

While scholars have warned that there may be serious learning consequences for Latina/o students who come from collectivistic cultures (La Roche \& Shriberg, 2004; Souto-Manning, 2009) as they move through the individualistic and competitive U.S. public school system (Glass \& Rud, 2012), they have also called for more studies around the relationship between cultural values and academic performance (Desmond \& López-Turley, 2009; Esparza \& Sánchez, 2008). As such, the present study incorporates the discrepancy between the frequency with which the Eurocentric values of individualism and competition are integrated in Latina/o students' home and school lives into a theoretical framework of cultural discontinuity to guide the methodological work. 


\section{Method}

\section{Participants}

Participants were 183 Latina/o (58\% male, 42\% female) 12th-grade students recruited from two high schools in two school districts near a large urban area in South Central Texas. Males were overrepresented among the participants, as the percentages of males and females in the two schools were equal (50\% each). However, the sample was largely representative of the ethnicities of the student bodies of the schools. Participants were self-selected, although all but $2 \%$ of the Latina/o students at one school agreed, with their parents' consent, to participate in the study, and all but 3\% of the Latina/o students at the other school participated in this research. The number of participants was deemed appropriate based on an acceptable ratio of 10 participants for each of the nine predictor variables examined in the study (Brace, Kemp, \& Snelgar, 2000).

The majority of participants identified English as the primary language they spoke at home (77\%) and reported being born in the United States (94\%). In addition, 65\% of participants reported that at least one of their parents was born in the United States. The majority of students also stated that they expected to graduate from a 4-year college or beyond (78\%); however, only $8 \%$ of their parents had done so. The mean number of advanced placement (AP) courses taken by the students in the sample was less than one with a large amount of variance, and the mean number of mathematics courses taken by the students was 3.7. The mean GPA for the sample was 84.12 , or 3.0 on a 4.0 grading scale as determined by The College Board (2011). Lastly, the mean mathematics standardized test score among participants was 2,219.43. The characteristics of student participants are summarized in Table 1.

[Insert Table 1 here] 


\section{Data Collection}

Data were collected via a self-administered questionnaire. In addition to survey information, participants' demographic and academic data were accessed through academic transcripts. The information gleaned from student records included participants' age, gender, ethnicity, GPA, standardized test scores, and enrollment in AP courses and mathematics courses.

Items were adapted from the Self-Construal Scale (SCS; Singelis, 1994). The SCS was designed to measure the strength of an individual's interdependent and independent selfconstruals that correspond to the constructs of collectivism and individualism. A sample item from this measure is, "I tend to do my own thing, and others in my family do the same." Additional items were drawn from a meta-analysis of individualism and collectivism domains assessed in individualism-collectivism scales (Oyserman, Coon, \& Kemmelmeier, 2002) and were used to assess the cultural values of individualism and competition, thought to measure the components of a broader factor labeled cultural discontinuity (Singelis, 1994). Singelis (1994) reported Cronbach's alpha reliability of .69 for the Independent subscale of the SCS. The present study found this measure to demonstrate similar reliability for the current sample (Cronbach's alpha $=.67)$. Validity was determined by the instrument's use in multiple published studies (e.g., Schwartz, 2007; Shorey et al., 2002).

Each item was reworded to operationalize specific behaviors, activities, or practices that students may experience at home and at school (Tyler et al., 2008). Items measured the frequency with which specific behaviors occur, each of which was measured twice. First, behaviors were measured for the frequency with which they occur at home. Next, they were measured for the frequency with which the behavior occurs at school. For example, one item stated, "In my home, I am singled out for praise and rewards," followed by, "In my school, I am 
singled out for praise and rewards." For each of the items, a four-point Likert-type scale was used with the following possible responses: $4=$ always, $3=$ sometimes, $2=$ rarely, $1=$ never. After the questionnaire was administered, a cultural discontinuity score was computed by subtracting the school score from the home score. Scores that did not equal zero were considered to evidence discontinuity between home and school, and absolute values were then used to regress cultural discontinuity against Latina/o students' academic performance (Tyler et al., 2008). A complete list of survey items can be found in the appendix.

\section{Predictor Variables}

Four blocks of variables were hypothesized to be related to Latina/o students' academic achievement. Demographic variables were included in the first block of the model, including gender, primary language, student's generational status, and the generational status of at least one parent. Next, socio-cultural variables were added to the second block of the model, including students' educational aspirations and the level of education of at least one parent. Third, academic experiences were added to the model, including the number of AP courses that a student had taken in high school and the number of mathematics courses that a student had taken. Finally, the cultural discontinuity variable was added as the last block of the model, comprising the scores obtained from the questionnaire for cultural discontinuity based on the Eurocentric cultural values of individualism and competition.

A coefficient of determinant $\left(\mathrm{R}^{2}\right.$ change) was used to determine whether the addition of each new block of variables resulted in an overall improvement in the fit of the model (i.e., the degree to which the dependent variable is predicted). In addition, outliers, multicollinearity, nonlinearity, and non-normality were examined when assessing the fit of the model. The standard error was also examined. 


\section{Outcome Variables}

The outcome examined in the present study was academic achievement. This outcome was measured by cumulative GPA and mathematics standardized test scores. The selection of GPA as a unit of measurement was informed by its use in prior research (e.g., O'Connor, 2009; Zwick \& Sklar, 2005). For the purpose of clarity, GPA is presented in this study by its value from The College Board's (2011) 4.0 scale, which approximates GPA from a range of possible scores.

In addition, scores from the Texas state-mandated standardized test, named the Texas Assessment of Knowledge and Skills (TAKS), were examined for the last administration of the TAKS test that the participants had taken. Mathematics TAKS scores were chosen as the unit of measurement because previous research has shown that achievement in mathematics is strongly linked to student academic achievement (e.g., C. R. Cooper et al., 2002; Sciarra \& Whitson, 2007). When reporting TAKS scores, the Texas Education Agency converts raw TAKS scores into scale scores that are common to all test forms for each assessment. For the academic year when the participants in this study took the exit-level TAKS mathematics examination, scale scores ranged from 1,302 to 2,839 with a score of 2,100 considered to be a passing mathematics score (Texas Education Agency, 2010).

\section{Data Analyses}

Descriptive statistics were computed to explore and compare the characteristics of students who experienced higher and lower levels of cultural discontinuity between home and school. In addition, $\mathrm{t}$ tests were computed for interval- or ratio-level variables (such as number of mathematics courses taken) to identify significant differences between the means of students who experienced higher and lower levels of cultural discontinuity between their home- and 
school- based learning and social experiences, as well as to determine whether or not there were significant differences in the cumulative GPA and mathematics TAKS scores of high school students who experienced higher and lower levels of cultural discontinuity between home and school. Chi-square tests for independence were calculated to discover whether significant relationships existed between categorical variables (Cronk, 2010). Lastly, effect sizes were calculated and examined for practical significance (Bracey, 2000).

Using block sequential modeling, hierarchical multiple regression was conducted to identify which variables were associated with academic achievement and to determine the percent of variance in the outcomes that could be explained by the predictor variables (Garson, 2008). The regression equation was calculated as follows:

$$
Y=\beta_{0}+\beta_{1} X_{1}+\beta_{2} X_{2}+\ldots+\beta_{\mathrm{z}} X_{\mathrm{z},}
$$

where $\beta$ is the regression coefficient, $\mathrm{z}$ is the number of independent variables, $\mathrm{Y}$ is the dependent variable, and the Xs are the independent variables (Cronk, 2010).

Data analyses were conducted using PASW Statistics 18 except for the determination of participants' cultural discontinuity scores, which were calculated in Microsoft Excel. A probability level of .05 was set for each research hypothesis. Prior to analyses, data were screened for skewness and outliers and then examined for test assumptions (Mertler \& Vannatta, 2010). Missing data were handled using multiple imputations (MI) with LISREL 8.80 (Enders, 2008).

\section{Data Limitations}

Certain limitations must be taken into account when considering the findings of this study. First, the study was concerned with two high schools in a specific geographical area, thereby limiting its generalizability to other educational institutions and populations. Next, the 
study was limited by the number of respondents and their parents/legal guardians who were willing to participate in the data collection. Moreover, the survey itself does not account for all possible cultural discontinuities that Latina/o students may experience between home and school, but only cultural discontinuity based on certain cultural values found to be most often discussed in the literature. Similarly, the researcher did not have access to all the variables previously found in the literature to impact student achievement (e.g., participants' socio-economic status [SES]) and was thereby limited to the variables to which she had access. Finally, survey research alone cannot reveal the rich and complex data (Conchas, 2001) that could be obtained through interviews with students and observations of classrooms and other school settings.

\section{Results}

\section{Descriptive Findings}

Descriptive statistics were used to investigate significant differences between the characteristics and academic outcomes of Latina/o high school students who did and did not experience cultural discontinuity between their home- and school-based learning and social experiences. Nearly all the participants were found to have experienced some cultural discontinuity between home and school. Therefore, to determine which students experienced higher and lower levels of cultural discontinuity, the mean (.406) and standard deviation (.391) of the cultural discontinuity scores were examined. Participants with cultural discontinuity scores that were at least one standard deviation above the mean (.797) were considered to have experienced higher levels of cultural discontinuity, whereas participants with cultural discontinuity scores at least one standard deviation below the mean (.015) were considered to have experienced lower levels of cultural discontinuity. These scores were then used to 
descriptively compare the characteristics of students who experienced higher and lower levels of cultural discontinuity between home and school based on Eurocentric cultural values.

A descriptive comparison of students who experienced higher levels of cultural discontinuity $(n=32)$ between home and school based on Eurocentric cultural values and students who experienced lower levels of cultural discontinuity $(n=25)$ between home and school based on Eurocentric cultural values revealed numerous differences between the two groups. Male students were more likely to have reported experiencing lower levels of cultural discontinuity than were females (64\% vs. $36 \%$ ). Nearly equal percentages of students whose primary home language was English indicated that they experienced either high (78\%) or low (76\%) levels of cultural discontinuity between home and school. In addition, $96 \%$ of students who reported experiencing low levels of cultural discontinuity were born in the United States, whereas $91 \%$ of students who experienced high levels of cultural discontinuity were born in the United States. However, students with at least one parent born outside of the United States reported experiencing higher levels of cultural discontinuity (69\%) in comparison with students who experienced lower levels of cultural discontinuity (52\%). Students with higher levels of cultural discontinuity were more likely to expect to graduate from college than students with lower levels of cultural discontinuity ( $82 \%$ vs. $60 \%)$ and also had at least one parent who had graduated from college (13\% vs. $4 \%)$.

Chi-square tests of significance were also conducted to determine whether the independent variables were associated with levels of cultural discontinuity based on Eurocentric cultural values (i.e., higher levels/lower levels). No significant relationships were found for gender, $\chi^{2}(1)=0.350, p>.05$; primary language spoken at home, $\chi^{2}(1)=0.036, p>.05$; whether or not a student was born in the United States, $\chi^{2}(1)=0.621, p>.05$; whether or not at least one 
parent was born in the United States, $\chi^{2}(1)=0.251, p>.05$; whether or not a student expected to complete a 4-year college degree, $\chi^{2}(1)=3.139, p>.05$; and whether or not at least one parent had completed a 4-year college degree, $\chi^{2}(1)=1.361, p>.05$. Descriptive findings for cultural discontinuity based on Eurocentric cultural values are summarized in Tables 2 and 3.

[Insert Tables 2 and 3 here]

Next, descriptive statistics were used to determine whether or not there was a significant difference in the academic outcomes, as measured by cumulative GPA and mathematics TAKS scores, of Latina/o students who experienced higher and lower levels of cultural discontinuity between home and school based on the Eurocentric cultural values of individualism and competition. Students who experienced higher levels of cultural discontinuity had scaled GPAs equal to students who experienced lower levels of cultural discontinuity (3.0 GPA). An independent samples t-test was conducted to compare the mean GPA of students with higher levels of cultural discontinuity to the mean GPA of students with lower levels of cultural discontinuity. No significant difference was found, $\mathrm{t}(55)=1.38, p>.05$. The mean of students with higher cultural discontinuity $(\mathrm{M}=83.08, \mathrm{SD}=5.60)$ was not significantly different than the mean of students with lower cultural discontinuity $(\mathrm{M}=85.30, \mathrm{SD}=6.46)$.

Students who experienced higher levels of cultural discontinuity had higher mean mathematics TAKS scores than students who experienced lower levels of cultural discontinuity $(2,218.09$ vs. $2,196.60)$. An independent samples t-test was conducted to compare the mean mathematics TAKS scores of students with higher levels of cultural discontinuity with the mean mathematics TAKS scores of students with lower levels of cultural discontinuity. No significant difference was found, $\mathrm{t}(55)=-0.361, p>.05$. The mean of students with higher cultural discontinuity $(\mathrm{M}=2,218.09, \mathrm{SD}=123.25)$ was not significantly different than the mean of 
students with lower cultural discontinuity $(\mathrm{M}=2,196.60, \mathrm{SD}=307.22)$. The mean, standard deviation, and t value for GPA and mathematics TAKS scores are summarized in Table 3.

\section{Multiple Regression Findings}

The first hierarchical multiple regression analysis was conducted to determine which independent variables (demographic variables, socio-cultural variables, academic experiences, and cultural discontinuity) were the predictors of students' GPA. Tolerance was examined during data screening prior to the data analyses and was found to be adequate among the independent variables because coefficients for all independent variables included and excluded were above .1.

Regression results indicated that the blocks demographic variables, academic experiences, and cultural discontinuity significantly predicted GPA, $\mathrm{R}^{2}=.439, \mathrm{R}^{2} \mathrm{adj}=.332, \mathrm{~F}(9$, $110)=4.092, \mathrm{p}=.001$. Although the blocks themselves were found to be significant, not every variable in each block was found to be significant. This model accounted for $43.9 \%$ of the variance in students' GPA, which represents a large effect size, as accounting for $25 \%$ of the variability corresponds to a large effect in multiple regression analysis (Cohen, 1988). Significant predictors of GPA included gender $(p<.05)$, the number of AP courses in which a student was enrolled during high school $(p<.05)$, and cultural discontinuity based on Eurocentric cultural values $(p<.05)$. As hypothesized, cultural discontinuity based on Eurocentric cultural values had an inverse relationship with GPA $(\beta=-.194)$. In other words, the more cultural discontinuity based on Eurocentric cultural values that a student experienced, the lower was the student's GPA. Moreover, whether or not a student was enrolled in AP classes during high school had a positive relationship with GPA $(\beta=.363)$. Therefore, the more AP classes students took during high school, the higher were their GPAs. Table 4 displays the 
parameter estimates, significance values, and fit statistics for the regression model predicting GPA.

[Insert Table 4 here]

The second hierarchical multiple regression analysis was calculated to predict participants' mathematics TAKS scores based on demographic and socio-cultural variables, academic experiences, and level of cultural discontinuity experienced between home and school. Socio-cultural variables and academic experiences were significant in the regression equation, $\mathrm{F}(9,110)=5.223, \mathrm{p}=.001$, with an $\mathrm{R}^{2}$ of .691 , though cultural discontinuity based on Eurocentric cultural values was not significant. Gender $(p<.05)$, a student's expected level of education $(p<.05)$, and the number of AP courses in which a student was enrolled during high school $(p<.01)$ were significant predictors of mathematics TAKS scores. In addition, a student's expected level of education and the number of AP courses in which a student was enrolled during high school had positive relationships with mathematics TAKS scores. Therefore, the higher the level of education a student expected to achieve $(\beta=.358)$ and the more AP classes a student took during high school $(\beta=.518)$, the higher their mathematics TAKS scores. Table 5 shows the parameter estimates, significance values, and fit statistics for the regression model predicting mathematics TAKS scores.

[Insert Table 5 here]

\section{Discussion/Conclusion}

Results from this study contribute to our understanding of the variables influencing cultural discontinuity. Namely, this study advances prior efforts by documenting the role of cultural discontinuity in the academic outcomes of Latina/o high school students. Descriptive findings reveal several conclusions worthy of note. First, the findings corroborate the premise of 
this study, which is that mainstream schools may propagate specific cultural values and beliefs (e.g., Boykin, Tyler, \& Miller, 2005; Cholewa \& West-Olatunji, 2008; Ornstein et al., 2011) that may not reflect the cultural values of many racial/ethnic minority students (Cartledge \& Loe, 2001; Deyhle, 1995; Durden, 2007).

Findings also revealed that experiencing higher or lower levels of cultural discontinuity between home- and school-based learning and social experiences based on Eurocentric cultural values during high school influenced students' academic achievement as measured by GPA, with students who reported higher levels of cultural discontinuity having lower GPAs than students with lower levels of cultural discontinuity. This finding is important because grades have been shown to significantly affect racial/ethnic minority students' predispositions to attend college (e.g., Hamrick \& Stage, 2004) and because GPA is a crucial consideration in the college admissions process, with students who enroll in college and who have lower high school GPAs being less likely to be accepted to 4-year colleges (Stumpf \& Stanley, 2002) and more likely to attend 2-year colleges (Stokes \& Somers, 2009). Therefore, results suggest that cultural discontinuity may serve to advance or prohibit Latina/o students' college enrollment and college choice.

Moreover, students' expected level of educational attainment was found to contribute to both GPA and mathematics TAKS scores after controlling for other variables in the model. This finding supports prior research showing that levels of academic preparation and achievement may have a reciprocal relationship with educational aspirations, as academic preparation and achievement, including mathematics achievement, are positive predictors of high educational aspirations (i.e., aspiring to earn at least a bachelor's degree) among students (M. A. Cooper, 2009). 
One of the most important findings of the present study is that cultural discontinuity based on Eurocentric cultural values is a significant predictor of GPA but not mathematics TAKS scores. This finding merits an interesting discussion about the subjectivity of teachergiven grades and supposedly more objective standardized test scores. For many years, research has shown that teacher judgments of students' academic performance are confounded by bias (e.g., Pedulla, Airasian, \& Madaus, 1980). According to Sadler (2009), assessment bias may be a product of teachers' preconceptions against students who "display certain traits or attitudes" or "belong to particular ethnic, religious, racial, cultural or socioeconomic groups" (p. 812). In addition, bias may be the result of "assessment tasks that are not equally accessible to learners from different cultures" (Sadler, 2009, p. 813). Previous research has established that teachers' perceptions of differences between themselves and their students is frequently harmful to student success (e.g., Hauser-Cram et al., 2003; Tan, 2001, 2002; Thompson et al., 2004) and that these perceived differences many times produce in teachers diminished beliefs about their students' intelligence and ability (Cholewa \& West-Olatunji, 2008) as well as less acceptance of students' cultures and behaviors (Lovelace \& Wheeler, 2006). Because cultural discontinuity results from differences between students' home cultures and the dominant culture imposed on them at school, it is important to examine the bias that may be present in the teacher-given grades that make up a student's GPA.

A body of literature has reported on discrepancies in teachers' grading behavior and students' standardized test scores. For example, in a study of nearly 50,000 college freshmen across 23 schools in the United States, Kobrin, Camara, and Milewski (2002) found that 32\% of students had inconsistent GPA and SAT test scores, having a GPA that was either at least one standard deviation above or below SAT scores. Moreover, a study of 170 fifth-grade teachers 
revealed that teacher judgments of students' IQ, English, and mathematics performance were affected by their judgments of other student behaviors (Pedulla et al., 1980). This research was supported by findings from a more recent study of a nationally representative sample of teachers of third- and fifth-grade students who participated in the Early Childhood Longitudinal Study, which revealed that $87 \%$ of teachers in the study reported using different standards for evaluating the achievement of at least some of their students, based on special need or perceived ability. However, among teachers who reported holding the same standards in evaluating all students in their classrooms with no accommodation made for disadvantage, teacher evaluations of students more closely resembled the achievement levels of students as shown by standardized test scores (Martínez, Stecher, \& Borko, 2009).

Findings from the present study support previous research by suggesting discrepancies in teacher-given grades and standardized test scores for Latina/o students, as cultural discontinuity based on Eurocentric cultural values was found to contribute to GPA but not standardized mathematics TAKS scores. In fact, students who experienced higher levels of cultural discontinuity based on Eurocentric cultural values were found to have lower GPAs than students who experienced lower levels of cultural discontinuity based on Eurocentric cultural values; however, the mathematics TAKS scores of students with higher levels of cultural discontinuity based on both Eurocentric cultural values were higher than for students who experienced lower levels of cultural discontinuity. These findings are important given that grades have been shown to have multiple effects on students, including influence on their self-esteem (e.g., Bankston \& Zhou, 2002), motivation (e.g., Faircloth \& Hamm, 2005), dropout rates (e.g., Balfanz, Herzog, \& Mac Iver, 2007), and college enrollment (e.g., Hamrick \& Stage, 2004). According to Stake (2002), employers and other readers of transcripts, such as college admissions personnel, lack the 
information they need to determine what grades mean for individual teachers. Given the results of this study, it is possible that the teacher-given grades of the student participants reflect teachers' emphasis on Eurocentric values and ideas as the correct way to learn (Solórzano \& Yosso, 2002), whereas the cultural values and styles of learning of their Latina/o students may not be as well rewarded.

\section{Recommendations for Future Research}

Although the findings from this study were limited to Latina/o students, it is recommended that further research explore cultural discontinuity as it relates to other racial/ethnic groups, including African Americans, American Indians, Asians, Pacific Islanders, and multiracial students. In addition, the definition of academic achievement used in this study (i.e., GPA and mathematics TAKS scores) could be changed or added to in future research to look at other measures of achievement such as high school graduation, college enrollment, or type of college in which a student enrolled after high school graduation (i.e., 2- or 4-year college).

Qualitative research should also be conducted to extract more vivid descriptions of the relationship between cultural discontinuity among diverse students in schools and its effect on their achievement outcomes. In addition, culturally relevant pedagogy should be empirically investigated as an antidote to cultural discontinuity.

Finally, in light of the conclusions drawn from the findings of this study that teacher perceptions of students and student behavior (cultural or otherwise) may affect their judgments of students' academic skills, it is recommended that further research examine teachers' grading practices for students from diverse racial/ethnic groups (Steward, Hill, Neil, Pritchett, \& Wabaunsee, 2008). Furthermore, research should examine the specific, observable behaviors and 
learning styles that contribute to teachers' judgments (Bennett, Gottesman, Rock, \& Cerullo,

1993; Wildhagen, 2009). 


\section{References}

American Psychological Association. (2003). Guidelines on multicultural education, training, research, practice, and organizational change for psychologists. American Psychologist, 58, 377-402. doi:10.1037/0003-066X.58.5.377

Arunkumar, R., Midgley, C., \& Urdan, T. (1999). Perceiving high or low homeschool dissonance: Longitudinal effects on adolescent emotional and academic well-being. Journal of Research on Adolescence, 9, 441-466.

Baker, P. B. (2005). The impact of cultural biases on African American students' education: A review of research literature regarding race based schooling. Education and Urban Society, 37, 243-256. doi:10.1177/0013124504274187

Balfanz, R., Herzog, L., \& Mac Iver, D. J. (2007). Preventing student disengagement and keeping students on the graduation path in urban middle-grades schools: Early identification and effective interventions. Educational Psychologist, 42, 223-235.

Banks, J. A. (2007). Educating citizens in a multicultural society (2nd ed.). New York, NY: Teachers College Press.

Bankston, C. L., \& Zhou, M. (2002). Being well vs. doing well: Self-esteem and school performance among immigrant and nonimmigrant racial and ethnic groups. The International Migration Review, 36, 389-415.

Barrett, A. N., Barile, J. P., Malm, E. K., \& Weaver, S. R. (2012). English proficiency and peer interethnic relations as predictors of math achievement among Latino and Asian immigrant students. Journal of Adolescence, 35, 1619-1628. 
Beachum, F. D., \& McCray, C. R. (2008). Dealing with cultural collision: What pre-service educators should know. In G. Goodman (Ed.), Educational psychology: An application of critical constructivism (pp. 53-70). New York, NY: Peter Lang.

Bennett, R. E., Gottesman, R. L., Rock, D. A., \& Cerullo, F. (1993). Influence of behavior perceptions and gender on teachers' judgments of students' academic skill. Journal of Educational Psychology, 85, 347-356.

Boykin, A. W., Albury, A., Tyler, K. M., Hurley, E. A., Bailey, C. T., \& Miller, O. A. (2005). Culture-based perceptions of academic achievement among low-income elementary students. Cultural Diversity \& Ethnic Minority Psychology, 11, 339- 350. doi:10.1037/1099-9809.11.4.339

Boykin, A. W., \& Cunningham, R. T. (2001). The effects of movement expressiveness in story content and learning context on the analogical reasoning performance of African American children. The Journal of Negro Education, 70, $72-83$.

Boykin, A. W., Tyler, K. M., \& Miller, O. (2005). In search of cultural themes and their expressions in the dynamics of classroom life. Urban Education, 40, 521-549. doi: $10.1177 / 0042085905278179$

Boykin, A. W., Tyler, K. M., Watkins-Lewis, K. M., \& Kizzie, K. (2006). Culture in the sanctioned classroom practices of elementary school teachers serving low-income African American students. Journal of Education for Students Placed at Risk, 11, 161173. doi:10.1207/s15327671espr1102_3

Brace, N., Kemp, R., \& Snelgar, R. (2000). SPSS for psychologists: A guide to data analysis using SPSS for windows. Mahwah, NJ: Lawrence Erlbaum. 
Bracey, G. W. (2000). Bail me out! Handling difficult data and tough questions about public schools. Thousand Oaks, CA: Corwin Press.

Cartledge, G., \& Loe, S. A. (2001). Cultural diversity and social skill instruction. Exceptionality, 9, 33-46.

Cazden, C. B., John, P., \& Hymes, D. (Eds.). (1972). Functions of language in the classroom. New York, NY: Teachers College Press.

Cholewa, B., \& West-Olatunji, C. (2008). Exploring the relationship among cultural discontinuity, psychological distress, and academic outcomes with low-income, culturally diverse students. Professional School Counseling, 12(1), 54-61.

Clark, M. A., Ponjuan, L., Orrock, J., Wilson, T., \& Flores, G. (2013). Support and barriers for Latino male students' educational pursuits: Perceptions of counselors and administrators. Journal of Counseling \& Development, 91, 458-466. doi:10.1002/j. 15566676.2013.00118.x

Cohen, J. (1988). Statistical power analysis for the behavioral sciences (2nd ed.). Mahwah, NJ: Lawrence Erlbaum.

The College Board. (2011). How to convert your GPA to a 4.0 scale. Retrieved from http://www.collegeboard.com/html/academicTracker-howtoconvert.html

Conchas, G. Q. (2001). Structuring failure and success: Understanding the variability in Latino school engagement. Harvard Educational Review, 71, 475-504.

Constantine, M. G., \& Sue, D. W. (2006). Factors contributing to optimal functioning in people of color in the United States. Counseling Psychologist, 34, 228-244. doi: $10.1177 / 0011000005281318$ 
Cooper, C. R., Cooper, R. G., Azmitia, M., Chavira, G., \& Gullatt, Y. (2002). Bridging multiple worlds: How African American and Latino youth in academic outreach programs navigate math pathways to college. Applied Developmental Science, 6, 73-87.

Cooper, M. A. (2009). Dreams deferred? The relationship between early and later postsecondary educational aspirations among racial/ethnic groups. Educational Policy, 23, 615-650.

Cronk, B. C. (2010). How to use PASW statistics: A step-by-step guide to analysis and interpretation (6th ed.). Glendale, CA: Pyrczak.

Cupito, A. M., Stein, G. L., \& Gonzalez, L. M. (2015). Familial cultural values, depressive symptoms, school belonging and grades in Latino adolescents: Does gender matter? Journal of Child and Family Studies, 24, 1638-1649. doi:10.1007/ s10826-014-9967-7

Delpit, L. (2006). Other people's children: Cultural conflict in the classroom. New York, NY: The New Press.

Desmond, M., \& López-Turley, R. N. (2009). The role of familism in explaining the HispanicWhite college application gap. Social Problems, 56, 311-334.

Deyhle, D. (1995). Navajo youth and Anglo racism: Cultural integrity and resistance. Harvard Educational Review, 65, 403-444.

Durden, T. R. (2007). African centered schooling: Facilitating holistic excellence for Black children. The Negro Educational Review, 58, 23-34.

Enders, C. K. (2008, March 25). Analysis of missing data. Paper presented at the meeting of the American Educational Research Association, New York, NY.

Esparza, P., \& Sánchez, B. (2008). The role of attitudinal familism in academic outcomes: A study of urban, Latino high school seniors. Cultural Diversity \& Ethnic Minority Psychology, 14, 193-200. doi:10.1037/1099-9809.14.3.193 
Faircloth, B. S., \& Hamm, J. V. (2005). Sense of belonging among high school students representing four ethnic groups. Journal of Youth and Adolescence, 34, 293-309. doi:10.1007/s10964-005-5752-7

Foster, M., Lewis, J., \& Onafowora, L. (2003). Anthropology, culture, and research on teaching and learning: Applying what we have learned to improve practice. Teachers College Record, 105, 261-277.

Garrett, M. T., Bellon-Harn, M. L., Torres-Rivera, E., Garrett, J. T., \& Roberts, L. C. (2003). Open hands, open hearts: Working with Native youth in the schools. Intervention in School and Clinic, 38, 225-235.

Garson, D. (2008). Logistic regression. North Carolina State University. Retrieved from http://faculty.chass.ncsu.edu/garson/PA765/logistic.htm

Glass, G. V., \& Rud, A. G. (2012). The struggle between individualism and communitarianism: The pressure of population, prejudice, and the purse. Review of Research in Education, 36, 95-112. doi:10.3102/0091732X11422863

Goldenberg, C., Gallimore, R., Reese, L., \& Garnier, H. (2001). Cause or effect? A longitudinal study of immigrant Latino parents' aspirations and expectations, and their children's school performance. American Educational Research Journal, 38, 547-582.

Goldring, R., Gray, L., \& Bitterman, A. (2013). Characteristics of public and private elementary and secondary school teachers in the United States: Results from the 2011-12 Schools and Staffing Survey (NCES 2013-314). Washington, DC: U.S. Department of Education, National Center for Education Statistics. Retrieved from http://nces.ed.gov/pubsearch 
Gonzalez, K. P., Stoner, C., \& Jovel, J. E. (2003). Examining the role of social capital in access to college for Latinas: Toward a college opportunity framework. Journal of Hispanic Higher Education, 2, 146-170. doi:10.1177/1538192702250620

González-Prendes, A. A., Hindo, C., \& Pardo, Y. (2011). Cultural values integration in cognitive-behavioral therapy for a Latino with depression. Clinical Case Studies, 10, 376394. doi: $10.1177 / 1534650111427075$

Greenfield, P. M., Flores, A., Davis, H., \& Salimkhan, G. (2008). What happens when parents and nannies come from different cultures? Comparing the caregiving belief systems of nannies and their employers. Journal of Applied Developmental Psychology, 29, 326-336. doi:10.1016/j.appdev.2008.04.002

Greenfield, P. M., Keller, H., Fuligni, A., \& Maynard, A. (2003). Cultural pathways through universal development. Annual Review of Psychology, 54, 461-490. doi:10.1146/annurev.psych.54.101601.145221

Greenfield, P. M., \& Quiroz, B. (2013). Context and culture in the socialization and development of personal achievement values: Comparing Latino immigrant families, European American families, and elementary school teachers. Journal of Applied Developmental Psychology, 34, 108-118. doi:10.1016/j.app-dev.2012.11.002

Guilamo-Ramos, V., Dittus, P., Jaccard, J., Johansson, M., Bouris, A., \& Acosti, N. (2007). Parenting practices among Dominican and Puerto Rican mothers. Social Work, 52, 17-30. Gutiérrez, K. D., \& Rogoff, B. (2003). Cultural ways of learning: Individual traits or repertoires of practice. Educational Researcher, 32(5), 19-25. doi:10.3102/0013 189X032005019 Halgunseth, L. C., Ispa, J. M., \& Rudy, D. (2006). Parental control in Latino families: An integrated review of the literature. Child Development, 77, 1282-1297. 
Hamrick, F. A., \& Stage, F. K. (2004). College predisposition at high-minority enrollment, lowincome schools. The Review of Higher Education, 27, 151-168.

Hannon, B. (2015). Hispanics' SAT scores: The influences of level of parental education, performance-avoidance goals, and knowledge about learning. Hispanic Journal of Behavioral Sciences, 37, 204-222. doi:10.1177/0739986315573249

Hauser-Cram, P., Sirin, S. R., \& Stipek, D. (2003). When teachers' and parents' values differ: Teachers' ratings of academic competence in children from low-income families. Journal of Educational Psychology, 95, 813-820. doi:10.1037/00220663.95.4.813

Hudley, C., \& Daoud, A. M. (2008). Cultures in contrast: Understanding the influence of school culture on student engagement. In C. Hudley \& A. E. Gottfried (Eds.), Academic motivation and the culture of school in childhood and adolescence (pp. 187-220). New York, NY: Oxford University Press.

Huerta, J., Watt, K. M., \& Reyes, P. (2013). An examination of AVID graduates' college preparation and postsecondary progress: Community college versus 4-year university students. Journal of Hispanic Higher Education, 12, 86-101. doi: $10.1177 / 1538192712467204$

Kearney, J. F., Fletcher, M., \& Dobrenov-Major, M. (2011). Nonaligned worlds of home and school: A case study of second-generation Samoan children. Journal of Family Studies, 17, 146-156.

Kobrin, J. L., Camara, W. J., \& Milewski, G. B. (2002, January). Students with discrepant high school GPA and SAT I scores (Research Notes, RN-15). New York, NY: The College Board. 
Komarraju, M., \& Cokley, K. O. (2008). Horizontal and vertical dimensions of individualismcollectivism: A comparison of African Americans and European Americans. Cultural Diversity \& Ethnic Minority Psychology, 14, 336-343. doi:10.1037/10999809.14.4.336

Ladson-Billings, G. (1995a). But that's just good teaching! The case for culturally relevant pedagogy. Theory Into Practice, 34, 159-165.

Ladson-Billings, G. (1995b). Toward a theory of culturally relevant pedagogy. American Educational Research Journal, 32, 465-491.

La Roche, M. J., \& Shriberg, D. (2004). High stakes exams and Latino students: Toward a culturally sensitive education for Latino children in the United States. Journal of Educational and Psychological Consultation, 15, 205-223.

Lopez, M. H., \& Fry, R. (2013). Among recent high school grads, Hispanic college enrollment rate surpasses that of whites. Pew Research Center. Retrieved from http://www.pewresearch.org/fact-tank/2013/09/04/hispanic-college-enrollment- ratesurpasses-whites-for-the-first-time/

Lopez, S. G., Garza, R. T., \& Gonzalez-Blanks, A. G. (2012). Preventing smoking among Hispanic preadolescents: Program orientation, participant individualism- collectivism, and acculturation. Hispanic Journal of Behavioral Sciences, 34, 323-339. doi:1 $0.1177 / 0739986311435901$

Losey, K. M. (1995). Mexican American students and classroom interaction: An overview and critique. Review of Educational Research, 65, 283-318.

Lovelace, S., \& Wheeler, T. R. (2006). Cultural discontinuity between home and school language socialization patterns: Implications for teachers. Education, 127, 303-309. 
Lui, P. P. (2015). Intergenerational cultural conflict, mental health, and educational outcomes among Asian and Latino/a Americans: Qualitative and meta-analytic review. Psychological Bulletin, 141, 404-446.

Marryshow, D., Hurley, E. A., Allen, B. A., Tyler, K. M., \& Boykin, A. W. (2005). Impact of learning orientation on African American children's attitudes toward high-achieving peers. American Journal of Psychology, 118, 603-618.

Marsiglia, F. F., Parsai, M., \& Kulis, S. (2009). Effects of familism and family cohesion on problem behaviors among adolescents in Mexican immigrant families in the Southwest United States. Journal of Ethnic \& Cultural Diversity in Social Work, 18, 203-220. doi:10.1080/153132000903070965

Martínez, J. E., Stecher, B., \& Borko, H. (2009). Classroom assessment practices, teacher judgments, and student achievement in mathematics: Evidence from the ECLS. Educational Assessment, 14, 78-102. doi:10.1080/10627190903039429

McHale, S. M., Updegraff, K. A., Kim, J., \& Cansler, E. (2009). Cultural orientations, daily activities, and adjustment in Mexican American youth. Journal of Youth and Adolescence, 38, 627-641.

Mejía-Arauz, R., Rogoff, B., Dexter, A., \& Najafi, B. (2007). Cultural variation in children's social organization. Child Development, 78, 1001-1014.

Mertler, C. A., \& Vannatta, R. A. (2010). Advanced and multivariate statistical methods: Practical application and interpretation (4th ed.). Glendale, CA: Pyrczak.

Morelli, G. A., Rogoff, B., Oppenheim, D., \& Goldsmith, D. (1992). Cultural variation in infants' sleeping arrangements: Questions of independence. Developmental Psychology, 28, 604-613. 
Mosier, C. E., \& Rogoff, B. (2003). Privileged treatment of toddlers: Cultural aspects of individual choice and responsibility. Developmental Psychology, 39, 1047-1060. doi:10.1037/00121649.39.6.1047

Mosqueda, E., \& Maldonado, S. I. (2013). The effects of English language proficiency and curricular pathways: Latina/os' mathematics achievement in secondary schools. Equity \& Excellence in Education, 46, 202-219. doi:10.1080/10665 684.2013.780647

National Center for Education Statistics. (2010a, July). Status and trends in the education of ethnic and racial minorities (NCES 2010-05). Retrieved from http://nces.ed.gov/pubs2010/2010015/indicator3_14.asp

National Center for Education Statistics. (2010b, July). Status and trends in the education of ethnic and racial minorities (NCES 2010-05). Retrieved from http://nces.ed.gov/pubs2010/2010015/tables/table_14c.asp

National Center for Education Statistics. (2013). State profiles. Retrieved from http://nces.ed.gov/nationsreportcard/states/

O’Connor, N. (2009). Hispanic origin, socio-economic status, and community college enrollment. The Journal of Higher Education, 80, 121-145.

Ogbu, J. U. (1982). Cultural discontinuities and schooling. Anthropology \& Education Quarterly, 13, 290-307.

Ornstein, A. C., Levine, D. U., \& Gutek, G. L. (2011). Foundations of education (11th ed.). Belmont, CA: Wadsworth.

Oyserman, D., Coon, H. M., \& Kemmelmeier, M. (2002). Rethinking individualism and collectivism: Evaluation of theoretical assumptions and meta-analyses. Psychological Bulletin, 128, 3-72. doi:10.1037//0033-2909.128.1.3 
Padilla, A. M., \& Gonzalez, R. (2001). Academic performance of immigrant and U.S.-born Mexican heritage students: Effects of schooling in Mexico and bilingual/English language instruction. American Educational Research Journal, 38, 727-742.

Pedulla, J. J., Airasian, P. W., \& Madaus, G. F. (1980). Do teacher ratings and standardized test results of students yield the same information? American Educational Research Journal, 17, 303-307.

Plunkett, S. W., \& Bámaca-Gómez, M. Y. (2003). The relationship between parenting, acculturation, and adolescent academics in Mexican-origin immigrant families in Los Angeles. Hispanic Journal of Behavioral Sciences, 25, 222-239. doi:10.1177/0739986303253629

Plunkett, S. W., Behnke, A. O., Sands, T., \& Choi, B. Y. (2009). Adolescents' reports of parental engagement and academic achievement in immigrant families. Journal of Youth and Adolescence, 38, 257-268. doi:10.1007/s10964-008-9325-4

Portes, P. R. (2001). Social and psychological factors in the academic achievement of children of immigrants: A cultural history puzzle. American Educational Research Journal, 38, 461492.

Rodriguez, J. L. (2002). Family environment and achievement among three generations of Mexican American high school students. Applied Developmental Science, 6, 88-94.

Rodriguez, N., Mira, C. B., Paez, N. D., \& Myers, H. F. (2007). Exploring the complexities of familism and acculturation: Central constructs for people of Mexican origin. American Journal of Community Psychology, 39, 61-77. doi:10.1007/ s10464-007-9090-7

Rogoff, B. (2003). The cultural nature of human development. New York, NY: Oxford University Press. 
Rogoff, B., Mistry, J., Göncü, A., \& Mosier, C. (1993). Guided participation in cultural activity by toddlers and caregivers. Monographs of the Society for Research in Child Development, 58(8), i-179.

Rothstein-Fisch, C., Trumbull, E., \& Garcia, S. G. (2009). Making the implicit explicit: Supporting teachers to bridge cultures. Early Childhood Research Quarterly, 24, 474486.

Rudolph, B., Cornelius-White, C., \& Quintana, F. (2005). Filial responsibility among Mexican American college students: A pilot investigation and comparison. Journal of Hispanic Higher Education, 4, 64-78. doi:10.1177/ 1538192704271667

Sadler, D. R. (2009). Grade integrity and the representation of academic achievement. Studies in Higher Education, 34, 807-826. doi:10.1080/03075070802706553

Santiago, C. D., Gudiño, O. G., Baweja, S., \& Nadeem, E. (2014). Academic achievement among immigrant and U.S.-born Latino adolescents: Associations with cultural, family, and acculturation factors. Journal of Community Psychology, 42, 735-747.

Schwartz, S. J. (2007). The applicability of familism to diverse ethnic groups: A preliminary study. The Journal of Social Psychology, 147, 101-118.

Schwartz, S. J., Waterman, A. S., Umaña-Taylor, A. J., Lee, R. M., Kim, S. y., Vazsonyi, A. T., . .. Williams, M. K. (2013). Acculturation and well-being among college students from immigrant families. Journal of Clinical Psychology, 69, 298-318. doi:10.1002/jclp.21847

Sciarra, D. T., \& Whitson, M. L. (2007). Predictive factors in postsecondary educational attainment among Latinos. Professional School Counseling, 10, 307-316. 
Segal, E. A., Gerdes, K. E., Mullins, J., Wagaman, M. A., \& Androff, A. (2011). Social empathy attitudes: Do Latino students have more? Journal of Human Behavior in the Social Environment, 21, 438-454. doi:10.1080/10911359.2011 .566445

Shorey, H. S., Cowan, G., \& Sullivan, M. P. (2002). Predicting perceptions of discrimination among Hispanics and Anglos. Hispanic Journal of Behavioral Sciences, 24(3), 3-22. doi:10.1177/0739986302024001001

Singelis, T. M. (1994). The measurement of independent and interdependent self-construals. Personality and Social Psychology Bulletin, 20, 580-591. doi: $10.1177 / 0146167294205014$

Slavin, R. E. (1982). What Research Says to the Teacher. Cooperative learning: Student teams. Washington, DC: National Education Association of the United States.

Solórzano, D. G., \& Yosso, T. J. (2002). Critical race methodology: Counter-storytelling as an analytical framework for education research. Qualitative Inquiry, 8, 23-44.

Souto-Manning, M. (2009). Educating Latino children: International perspectives and values in early education. Childhood Education, 85, 182-186.

Stake, J. E. (2002). Making the grade: Some principles of comparative grading. Journal of Legal Education 583, 4, 585-618.

Stark, P., \& Noel, A. M. (2015). Trends in high school dropout and completion rates in the United States: 1972-2012 (NCES 2015-015). Washington, DC: U.S. Department of Education, National Center for Education Statistics. Retrieved from http://nces.ed.gov/pubsearch

Steward, R. J., Hill, M. F., Neil, D. M., Pritchett, T., \& Wabaunsee, A. (2008). What does GPA in an urban high school actually mean? Educational Considerations, 36(1), 11-16. 
Stokes, T., \& Somers, P. (2009). Who enrolls in two-year colleges? A national study of price response. Journal of Student Financial Aid, 39(1), 4-18.

Stumpf, H., \& Stanley, J. C. (2002). Group data on high school grade point averages and scores on academic aptitude tests as predictors of institutional graduation rates. Educational and Psychological Measurement, 62, 1042-1052. doi:10.1177/001316440223809

Sue, D. W. (2004, November). Whiteness and ethnocentric monoculturalism: Making the “invisible" visible. American Psychologist, 59, 761-769.

Tan, G. (2001). "I want my teachers to like me": Multiculturalism and school dropout rates among Mexican Americans. Equity \& Excellence in Education, 34(2), 35- 42. doi:10.1080/1066568010340206

Tan, G. (2002). The need for multiculturalism in the classroom as perceived by Mexican American schoolchildren. Multicultural Education, 9(3), 21-24.

Texas Education Agency. (2010). TAKS raw score conversion tables for 2009-2010. Retrieved from http://www.tea.state.tx.us/student.assessment/taks/convtables/ yr10/

Theoharis, G. (2007). Social justice educational leaders and resistance: Toward a theory of social justice leadership. Educational Administration Quarterly, 43, 221-258.

Theoharis, G. (2008). Woven in deeply identity and leadership of urban social justice principals. Education and Urban Society, 41, 3-25.

Thompson, G. L., Warren, S., \& Carter, L. (2004). It's not my fault: Predicting high school teachers who blame parents and students for students' low achievement. The High School Journal, 87(3), 5-14.

Tillman, L. C. (2002). Culturally sensitive research approaches: An African-American perspective. Educational Researcher, 31(7), 3-12. doi: 10.3102/ 0013189X031009003 
Tyler, K. M., Boykin, A. W., Boelter, C. M., \& Dillihunt, M. L. (2005). Examining mainstream and Afro-cultural value socialization in African American households. Journal of Black Psychology, 31, 291-311. doi:10.1177/0095798405278199

Tyler, K. M., Boykin, A. W., \& Walton, T. R. (2006). Cultural considerations in teachers' perceptions of student classroom behavior and achievement. Teaching and Teacher Education, 22, 998-1005. doi:10.1016/j.tate.2006.04.017

Tyler, K. M., Uqdah, A. L., Dillihunt, M. L., Beatty-Hazelbaker, R., Conner, T., Gadson, N., . . . Stevens, R. (2008). Cultural discontinuity: Toward a quantitative investigation of a major hypothesis in education. Educational Researcher, 37, 280-297. doi:10.3102/0013189X08321459

Umaña-Taylor, A. D., Updegraff, K. A., \& Gonzales-Backen, M. A. (2011). Mexican-origin adolescent mothers' stressors and psychosocial functioning: Examining ethnic identity affirmation and familism as moderators. Journal of Youth and Adolescence, 40, 140-157. doi:10.1007/s10964-010-9511-z

Valenzuela, A., \& Dornbusch, S. M. (1994). Familism and social capital in the academic achievement of Mexican origin and Anglo adolescents. Social Science Quarterly, 75, 1836.

Vasquez-Salgado, Y., Greenfield, P., M., \& Burgos-Cienfuegos, R. (2015). Exploring homeschool value conflicts: Implications for academic achievement and well-being among Latino first-generation college students. Journal of Adolescent Research, 30, 271-305. doi: $10.1177 / 0743558414561297$

Vélez-Ibáñez, C. G. (1996). Border visions: Mexican cultures of the Southwest United States. Tucson: The University of Arizona Press. 
Warikoo, N., \& Carter, P. (2009). Cultural explanations for racial and ethnic stratification in academic achievement: A call for a new and improved theory. Review of Educational Research, 79, 366-394.

Warzon, K. B., \& Ginsburg-Block, M. (2008). Cultural continuity between home and school as a predictor of student motivation: What we know, what we need to learn, and implications for practice. In C. Hudley \& A. E. Gottfried (Eds.), Academic motivation and the culture of school in childhood and adolescence (pp. 121-145). New York, NY: Oxford University Press.

Wildhagen, T. (2009). Why does cultural capital matter for high school academic performance? An empirical assessment of teacher-selection and self-selection mechanisms as explanations of the cultural capital effect. The Sociological Quarterly, 50, 173-200.

Zarate, M. E., \& Pineda, C. G. (2014). Effects of elementary school home language, immigrant generation, language classification, and school's English learner concentration on Latinos' high school completion. Teachers College Record, 116, 1-37.

Zwick, R., \& Sklar, J. (2005). Predicting college grades and degree completion using high school grades and SAT scores: The role of student ethnicity and first language. American Educational Research Journal, 42, 439-464. 


\section{Appendix}

\section{Items Analyzed From the Survey Instrument}

Individualism

In my home/school, I make my own choices rather than listen to others.

In my home/school, I speak up when I want to.

In my home/school, I am singled out for praise or rewards.

In my home/school, I take care of myself.

In my home/school, I tend to do my own thing, and others do the same.

\section{Competition}

In my home/school, I try to perform better than others on a task.

In my home/school, adults make it obvious when children are not doing well on their work.

In my home/school, adults tell me how I compare with others.

In my home/school, adults point out others who do well at something as an example to me.

In my home/school, adults encourage me to compete against others. 


\section{Table 1}

Characteristics of Study Participants

\begin{tabular}{l|lllll}
\hline & \multicolumn{4}{c}{ Sample Characteristics $(n=183)$} \\
\cline { 2 - 6 } Variable & & $\mathrm{n}$ & $\%^{\mathrm{a}}$ & $\mathrm{M}$ & $\mathrm{SD}$ \\
\hline
\end{tabular}

Demographic variables

Gender

Male

$106 \quad 58$

Female

Primary language spoken at home

English

$140 \quad 77$

Not English

$43 \quad 24$

Student born in the United States

Yes

No

At least one parent born in the United States

Yes

No

Unknown

Socio-cultural variables

Student expected level of education

Complete a 4-year college degree

Not complete a 4-year college degree

$14 \quad 78$

$41 \quad 22$

Education level of at least one parent

Completed a 4-year college degree

Did not complete a 4-year college
$172 \quad 94$

$11 \quad 6$

$119 \quad 65$

$12 \quad 12$

$42 \quad 23$ 
degree

Unknown

$30 \quad 16$

Academic experiences

Units in AP

$0.67 \quad 1.44$

Units in mathematics

$3.70 \quad 0.74$

Cultural discontinuity

Cultural discontinuity score based on

$0.41 \quad 0.39$ Eurocentric cultural values

Outcome variables

GPA

$3.0 \quad 8.79$

TAKS score

$2,219.43 \quad 218.94$

Note. AP = Advanced Placement; GPA = grade point average; TAKS $=$ Texas Assessment of Knowledge and Skills.

${ }^{a}$ Due to rounding, percentages may not equal $100 \%$. 


\section{Table 2}

Descriptive Comparison of Students Who Experienced Higher and Lower Levels of Cultural Discontinuity between Home and School Based on Eurocentric Cultural Values

\begin{tabular}{|c|c|c|}
\hline & $\begin{array}{c}\text { Students with higher } \\
\text { levels of cultural } \\
\text { discontinuity }\end{array}$ & $\begin{array}{c}\text { Students with lower } \\
\text { levels of cultural } \\
\text { discontinuity }\end{array}$ \\
\cline { 2 - 3 }$\%(n=32)$ & $\%(n=25)$ \\
\hline
\end{tabular}

Demographic variables

Gender

Male

Female

Primary language spoken at home

English

Not English

Student born in the United States

Yes

No

At least one parent born in the United States

Yes

No

Unknown

Socio-cultural variables

Student expected level of education

Complete a 4-year college degree

Not complete a 4-year college degree

Education level of at least one parent
68.8

56.3

64.0

43.8

36.0

78.1

76

21.9

90.6

96.0

9.4

4.0

6.3

8.0

25.0

40.0

81.3

60.0

18.8

40.0 
Completed a 4-year college degree

Did not complete a 4-year college degree

Unknown
12.5

65.6

21.9
4.0

76.0

20.0 


\section{Table 3}

Mean, Standard Deviation, and $t$ Value for Academic Experiences, GPA, and Mathematics TAKS Scores for Cultural Discontinuity between Home and School Based on Eurocentric Cultural Values

\begin{tabular}{|c|c|c|c|c|c|}
\hline & \multicolumn{2}{|c|}{$\begin{array}{l}\text { Students with higher } \\
\text { levels of cultural } \\
\text { discontinuity } \\
(n=32)\end{array}$} & \multicolumn{2}{|c|}{$\begin{array}{l}\text { Students with lower } \\
\text { levels of cultural } \\
\text { discontinuity } \\
(n=25)\end{array}$} & \multirow[b]{2}{*}{$t$} \\
\hline & M & $\mathrm{SD}$ & M & $\mathrm{SD}$ & \\
\hline \multicolumn{6}{|l|}{ Academic experiences } \\
\hline Units in AP & 0.61 & 1.51 & 0.31 & 1.02 & -0.871 \\
\hline Units in mathematics & 3.63 & 0.73 & 3.55 & 0.50 & -0.487 \\
\hline GPA & $83.08(3.0)$ & 5.60 & $85.30(3.0)$ & 6.46 & 1.381 \\
\hline Mathematics TAKS scores & $2,218.09$ & 123.25 & $2,196.60$ & 307.22 & -0.361 \\
\hline
\end{tabular}

Note. GPA = grade point average; TAKS = Texas Assessment of Knowledge and Skills; $\mathrm{AP}=$ Advanced Placement. 


\section{Table 4}

Multiple Regression Model: Parameter Estimates and Model Evaluation Predicting GPA

\begin{tabular}{|c|c|c|c|}
\hline Variable & $\beta$ & $t$ & $\mathrm{SE}$ \\
\hline \multicolumn{4}{|l|}{ Demographic variables } \\
\hline Gender & .334 & $2.384 *$ & 1.595 \\
\hline English primary language or not & .030 & 0.165 & 3.067 \\
\hline Student born in the United States or not & -.149 & -0.923 & 3.686 \\
\hline Parent born in the United States or not & .038 & -0.195 & 3.713 \\
\hline \multicolumn{4}{|l|}{ Socio-cultural variables } \\
\hline Student expected level of education & .491 & 3.110 & 1.954 \\
\hline Education level of at least one parent & -.261 & -1.424 & 2.792 \\
\hline \multicolumn{4}{|l|}{ Academic experiences } \\
\hline Units in AP & .363 & $1.791 *$ & 1.061 \\
\hline Units in mathematics & .069 & 0.340 & 1.924 \\
\hline \multicolumn{4}{|l|}{ Cultural discontinuity } \\
\hline $\begin{array}{l}\text { Cultural discontinuity score based on } \\
\text { Eurocentric cultural values }\end{array}$ & -.194 & $-1.153 *$ & 1.937 \\
\hline
\end{tabular}

Note. $\mathrm{GPA}=$ grade point average; $\mathrm{AP}=$ Advanced Placement.

$* p<.05$. 


\section{Table 5}

Multiple Regression Model: Parameter Estimates and Model Evaluation Predicting Mathematics TAKS Scores

\begin{tabular}{|c|c|c|c|}
\hline Variable & $\beta$ & $t$ & SE \\
\hline \multicolumn{4}{|l|}{ Demographic variables } \\
\hline Gender & -.274 & $-2.177^{*}$ & 30.281 \\
\hline English primary language or not & .032 & 0.194 & \\
\hline Student born in the United States or not & -.026 & -0.178 & \\
\hline Parent born in the United States or not & .040 & 0.229 & \\
\hline \multicolumn{4}{|l|}{ Socio-cultural variables } \\
\hline Student expected level of education & .358 & $2.532 *$ & \\
\hline Education level of at least one parent & .026 & 0.157 & \\
\hline \multicolumn{4}{|l|}{ Academic experiences } \\
\hline Units in AP & .518 & $2.857 * *$ & \\
\hline Units in mathematics & .162 & 0.893 & \\
\hline \multicolumn{4}{|l|}{ Cultural discontinuity } \\
\hline $\begin{array}{l}\text { Cultural discontinuity score based } \\
\text { on Eurocentric cultural values }\end{array}$ & -.031 & -0.208 & \\
\hline
\end{tabular}

Note. TAKS = Texas Assessment of Knowledge and Skills; AP = Advanced Placement. $* p<.05 . * * p<.01$. 